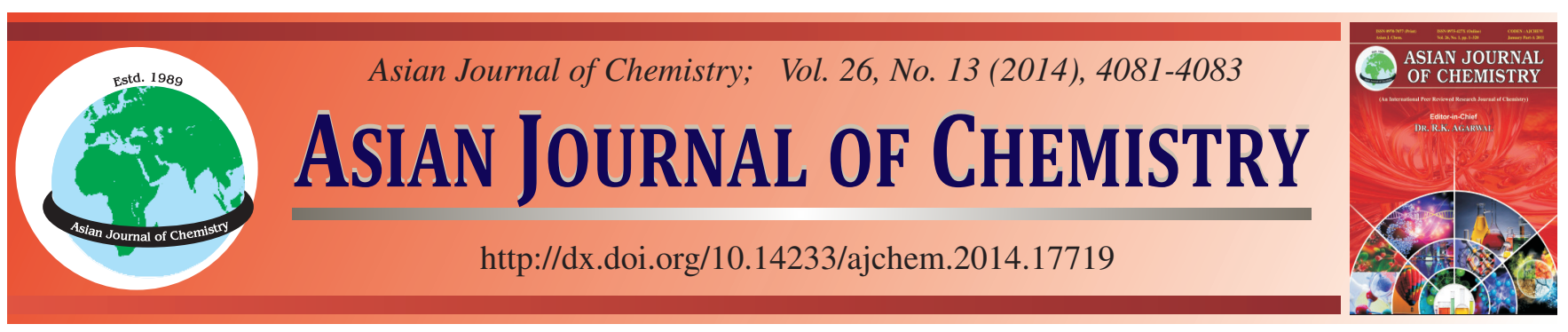

\title{
One-Step Detection of Explosives Using a Self-Developed Computer Program Based on Application of a Principal Component Analysis in Prompt $\gamma$-Spectra $\dagger$
}

Hee-Jung Im*, Yun-Hee Lee, Byoung Chul Song and Yong Joon Park

Nuclear Chemistry Research Division, Korea Atomic Energy Research Institute, 150 Deokjin-dong, Yuseong-gu, Daejeon 305-353, Republic of Korea

*Corresponding author: Fax: +82 42 8688148; E-mail: imhj@kaeri.re.kr

\begin{abstract}
A one-step process for the detection of an explosive was developed from tests and experimental data, and the achieved detection was based on the samples' relative elemental composition ratios. According to a self-developed computer program, collected $\gamma$-spectra by prompt $\gamma$-ray neutron activation analysis were applied to a principal component analysis to increase the signal-to-noise ratio and to discriminate the explosives from non-explosive materials. A test sample was successfully run through the program and could be detected as an explosive or a non-explosive with a reasonable error rate.
\end{abstract}

Keywords: Prompt $\boldsymbol{\gamma}$-ray neutron activation analysis, Principal component analysis, Pattern recognition, Explosives.

\section{INTRODUCTION}

Prompt $\gamma$-rays emitted from the interaction of neutrons with various materials were measured by a prompt $\gamma$-ray neutron activation analysis (PGNAA) system of the highflux advanced neutron application reactor (HANARO) ${ }^{1}$ or a deuterium-deuterium neutron generator (D-D NG) ${ }^{2}$ at the Korea Atomic Energy Research Institute (KAERI), with the aim of analyzing the major component elements in both aqueous and solid samples.

Plastic or military explosive materials are mainly composed of TNT (2,4,6-trinitrotoluene; $\left.\mathrm{C}_{7} \mathrm{H}_{5} \mathrm{~N}_{3} \mathrm{O}_{6}\right)$, RDX (hexahydro-1,3,5-trinitro-1,3,5-triazine; $\mathrm{C}_{3} \mathrm{H}_{6} \mathrm{~N}_{6} \mathrm{O}_{6}$ ), PETN (pentaerythritol tetranitrate; $\left.\mathrm{C}_{5} \mathrm{H}_{8} \mathrm{~N}_{4} \mathrm{O}_{12}\right)$ and $\mathrm{HMX}(1,3,5,7-$ tetranitro-1,3,5,7-tetrazacyclooctane; $\mathrm{C}_{4} \mathrm{H}_{8} \mathrm{~N}_{8} \mathrm{O}_{8}$ ) explosive substances, with a number of organic compounds such as waxes, plasticizers, stabilizers, oils, dyes, waterproof coatings and fabrics, although the mixing compositions, concentrations and containers are various and gradually more complicated ${ }^{3,4}$. Elements of the explosive substances are usually combinations of carbon $(\mathrm{C})$, hydrogen $(\mathrm{H})$, oxygen $(\mathrm{O})$ and nitrogen $(\mathrm{N})$, and their relative elemental composition ratios of $\mathrm{C} / \mathrm{N}, \mathrm{O} / \mathrm{N}$, $\mathrm{C} / \mathrm{O}$ or $\mathrm{C} / \mathrm{N}$ are similar to each other but different from those of non-explosive materials to be separated enough ${ }^{5}$.

If the neutron sources are radioisotopes or a compact neutron generator, and the detection method based on the relative elemental composition ratios is systematized for the reasonable practical screening in a short time period by lowering the signal to noise ratios, the use will be effective in the field and other broad areas. Therefore, a one-step process including all of these functions to detect explosives among suspicious materials is necessary, and a self-developed computer program for the effective detection of explosives is introduced here.

\section{EXPERIMENTAL}

As samples for obtaining experimental prompt $\gamma$-spectra, non-explosive materials [MEL (melamine; $\mathrm{C}_{3} \mathrm{H}_{6} \mathrm{~N}_{6}$ ), $\mathrm{KCl}$ (potassium chloride), PE (polyethylene; $\left.\left(-\mathrm{C}_{2} \mathrm{H}_{4}-\right)_{\mathrm{n}}\right)$, Cell (cellulose; $\left.\left(-\mathrm{C}_{6} \mathrm{H}_{10} \mathrm{O}_{5^{-}}\right)_{\mathrm{n}}\right)$, PAN (1-(2-pyridylazo)-2 naphtol; $\left.\mathrm{C}_{15} \mathrm{H}_{11} \mathrm{~N}_{3} \mathrm{O}\right)$, Urea $\left(\mathrm{CH}_{4} \mathrm{~N}_{2} \mathrm{O}\right), \mathrm{S}$ (sulfur powder), $\mathrm{P}$ (di-phosphorpentoxid; $\mathrm{P}_{2} \mathrm{O}_{5}$ ), PVC (polyvinyl chloride; $\mathrm{C}_{2} \mathrm{H}_{3} \mathrm{Cl}$ ), Acr (acrylic; $\mathrm{C}_{12} \mathrm{H}_{12} \mathrm{~N}_{4}$ ), $\mathrm{Nyl}$ (nylon; $\left.\mathrm{C}_{11} \mathrm{H}_{26} \mathrm{~N}_{2} \mathrm{O}_{4}\right)$ and sample $\mathrm{A}\left(\mathrm{C}_{3} \mathrm{H}_{6} \mathrm{~N}_{3} \mathrm{O}_{6}\right)$ ], which contain $\mathrm{C}, \mathrm{H}, \mathrm{O}$ and $\mathrm{N}$ as in explosive materials were prepared. Explosive materials [NB (nitrobenzene; $\mathrm{C}_{6} \mathrm{H}_{5} \mathrm{NO}_{2}$ ), $\mathrm{NP}$ (4-nitrophenol; $\mathrm{C}_{6} \mathrm{H}_{5} \mathrm{NO}_{3}$ ), TP (triethyl phosphate; $\mathrm{C}_{6} \mathrm{H}_{15} \mathrm{O}_{4} \mathrm{P}$ ), ABA (aminobenzoic acid; $\mathrm{C}_{7} \mathrm{H}_{7} \mathrm{NO}_{2}$ ), EGDN (ethylene glycol dinitrate; $\mathrm{C}_{2} \mathrm{H}_{4} \mathrm{~N}_{2} \mathrm{O}_{6}$ ) and PETN], which are explosive substances, isomers, or imitators prepared from a mixture of $\mathrm{PE}$, $\mathrm{NaNO}_{2}, \mathrm{NaNO}_{3}$ and $\mathrm{Na}_{2} \mathrm{CO}_{3}$ for reproducing the same relative concentrations of $\mathrm{C}, \mathrm{H}, \mathrm{O}$ and $\mathrm{N}$ as in real explosives were 
also prepared. Each sample and a blank (an empty Teflon vial itself) were irradiated for $1000 \mathrm{~s}$ at the HANARO PGNAA facility. All details of the sample preparation methods and neutron irradiation conditions were reported in a previously published paper $^{1}$.

\section{RESULTS AND DISCUSSION}

Fig. 1 shows the $\gamma$-spectra of MEL obtained from the HANARO research reactor (Fig. 1(a)) and the Monte Carlo N-particles transport code (MCNP-4C) simulation (Fig. 1(b)). The spectra were compared each other to verify the consistency of the relevant nuclear data inputs, and as expected, the spectral features from the Monte-Carlo N-particle simulation were fairly simpler than those from HANARO due to low data collecting points and the limited input parameters to be controlled. All simulated (14 explosives' and 12 non-explosives') and experimental $\gamma$-spectra were used to figure out the tendency of noise reduction ${ }^{6}$ and pattern recognition ${ }^{7}$, after to make and optimize a framework of the detection-process system.
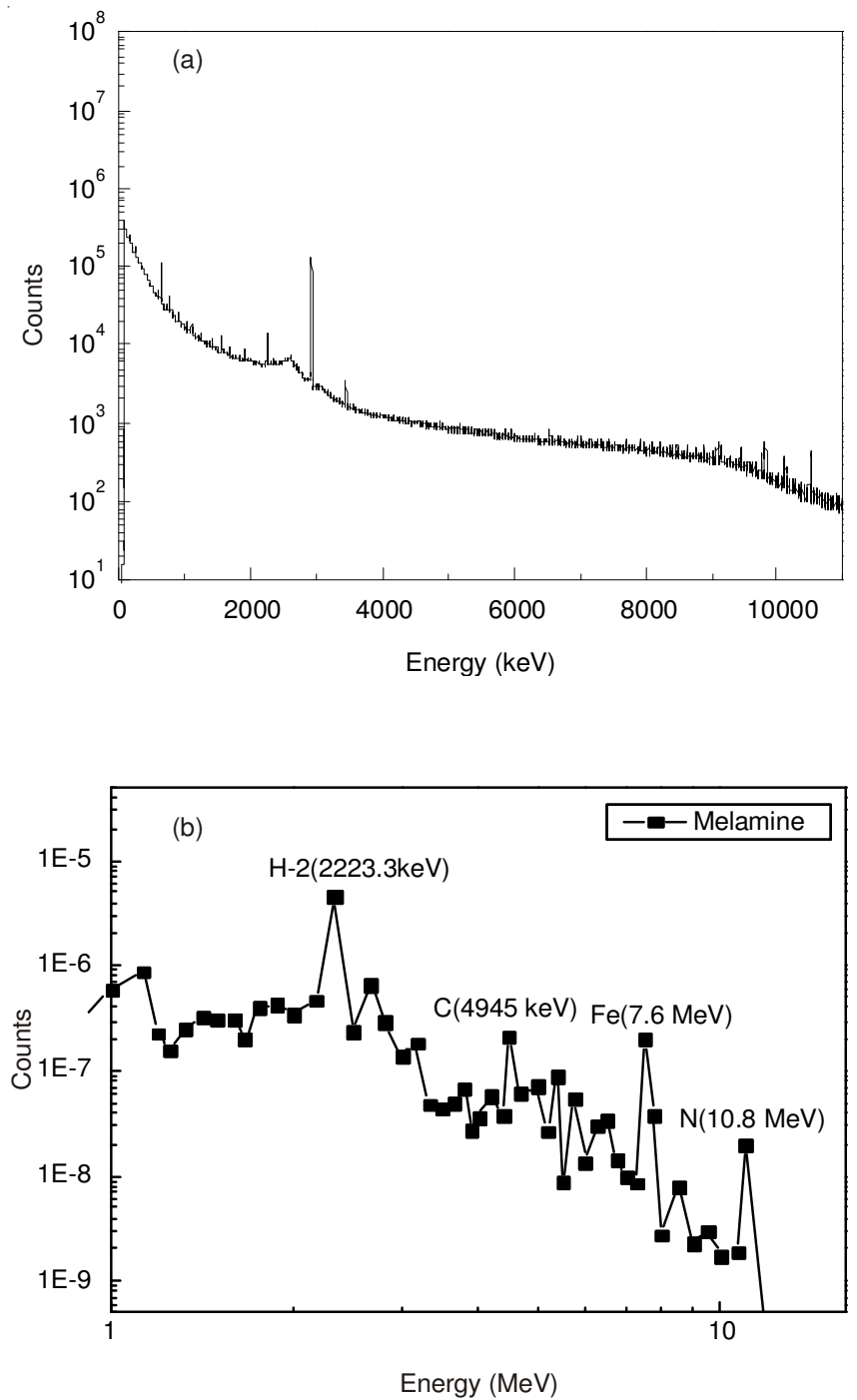

Fig. 1. Prompt $\gamma$-spectra of MEL obtained from (a) the HANARO research reactor and (b) MCNP simulation
To develop suitable discriminant classes with which suspect samples could be examined and determined as explosives or non-explosives, the $\gamma$-spectra obtained using the PGNAA facility at the 24 MW HANARO research reactor were used as history data. Thus, a scanned $\gamma$-spectrum of the suspicious sample can be projected into the history data for noise reduction and pattern recognition.

A principal component analysis (PCA), which is a multivariate statistical technique, is closely related to singular value decomposition (SVD) of the data matrix. The SVD-based PCA decreases the noise by reconstructing the spectrum after determining the number of principal components corresponding important signals based on the history data that sufficiently describe its population ${ }^{6,8}$. Furthermore, pattern recognition of PCA for a judgment of similarity or difference between samples is also very effective as the result of a linear transformation of the data used. A visualized computer program performing the PCA of the above procedure was developed using the MATLAB 7.04 programming language (Fig. 2) ${ }^{9}$, with the following computer algorism (Fig. 3$)^{10}$.

As shown in Figs. 2 and 3, an arbitrary measured spectrum of a suspect sample and history spectra are required as input files to run the program. Frame 1 in Fig. 2 is for the data loading of a calibrated energy-level file, the unknown sample's $\gamma$ spectrum file, a history 1 file for a noise reduction and a history 2 file for a pattern recognition of the unknown sample. If user selects the files with a menu, the program automatically carries out the PCA procedure and provides its noise-reduced spectrum plot as well as the original spectrum plot into an output window as a graph (frame 2-3) and a report (frame 24). In addition, the user can choose the number of principal components from the SCREE plot (frame 2-1 of Fig. 2) as the PCA results (frame 2-2 of Fig. 2) and obtain the signal-tonoise ratio of an interest peak by defining the peak and noise ranges ( 2 of Fig. 2) with the menu. The unknown sample's pattern recognition result (3-3 and 3-4 of Fig. 2) can also be obtained by following the same procedure as the noise reduction but using the noise-reduced $\gamma$-spectrum saved from the noise-reduction step.

$\gamma$-Spectra of several prepared non-explosive and explosive samples were projected into the developed detection program, and the detection results were correct within a $35 \%$ error rate. When the program is applied to the PGNAA system including a portable neutron generator, the detection of various types of the illicit materials could be easy to achieve within a very short period of time by comparing the $\gamma$-spectra of unknown samples' to the pre-programmed material signatures through the computer program.

\section{Conclusion}

Present method, as compared to other similar detection techniques, is to apply PCA for setting up a practical screening by pattern recognition after noise reduction in noisy prompt $\gamma$-spectra. To the best of our knowledge, there has been no such effective neutron based non-intrusive system to detect illicit materials in a short period of time. The PCA results and high penetration ability of the neutron and $\gamma$-rays contribute to reducing the probability of a false alarm for the determination of the presence of illicit materials. 


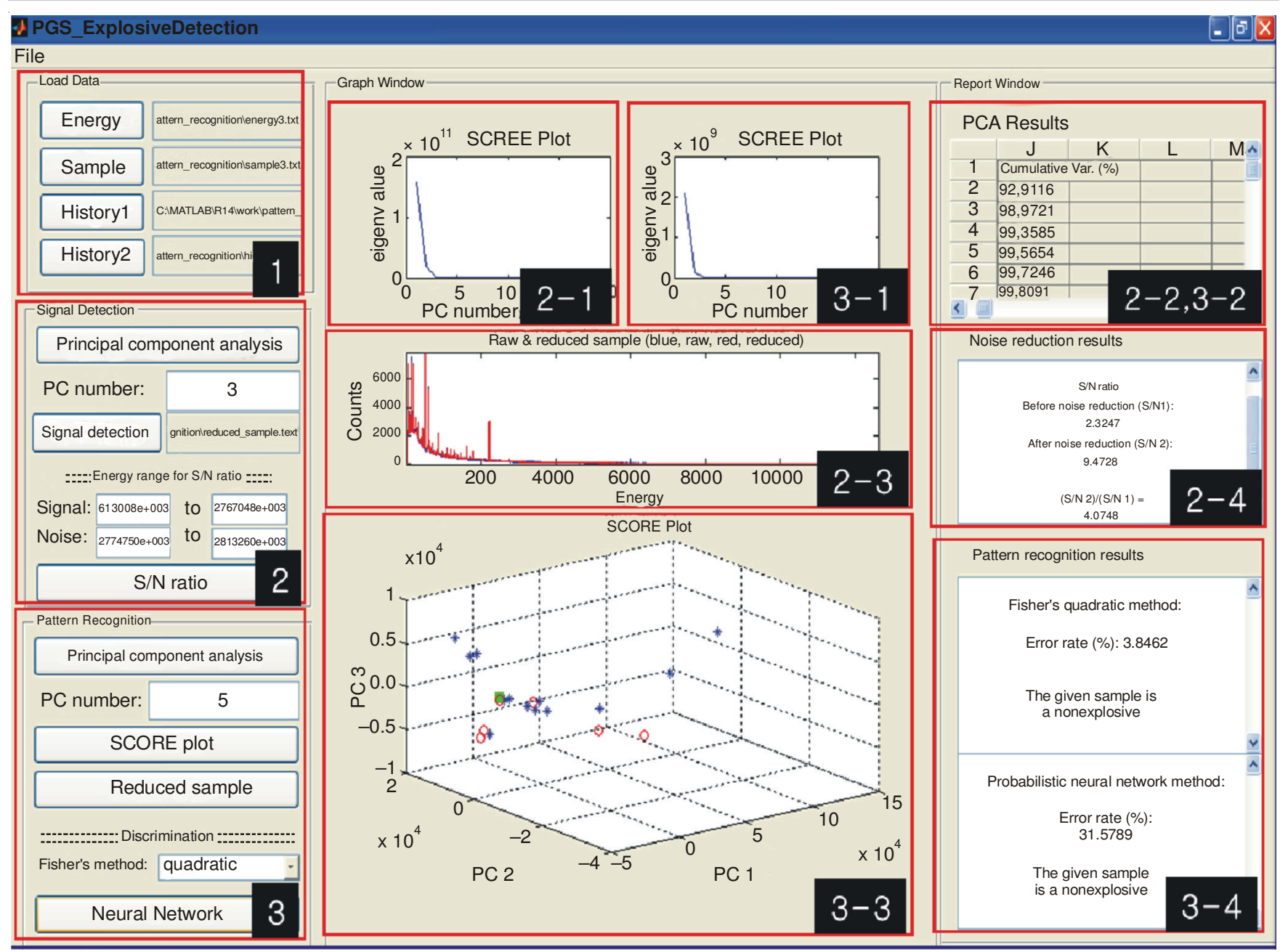

Fig. 2. Computer program developed in our laboratory for the detection of explosives [Ref. 10]

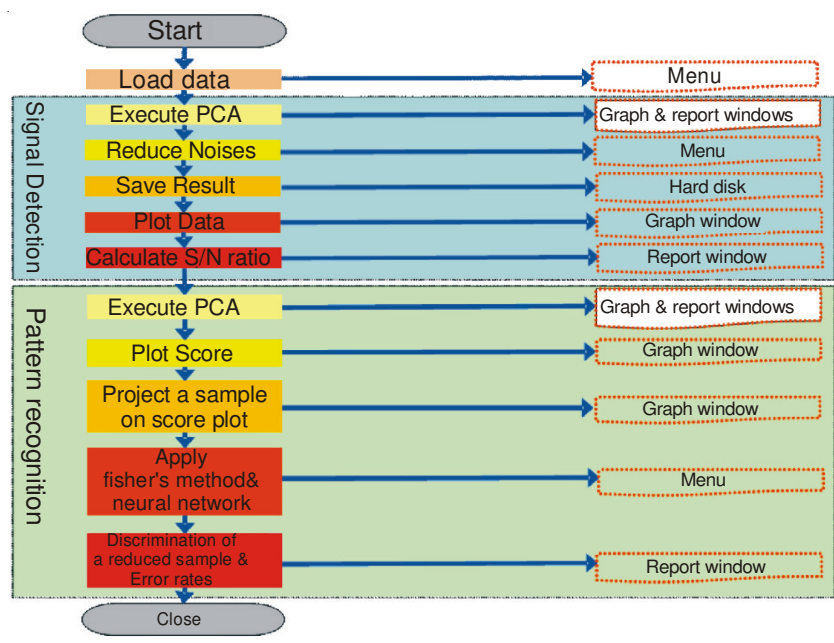

Fig. 3. Program algorism and the order of operation [Ref. 10]

\section{ACKNOWLEDGEMENTS}

This work was supported by the Nuclear Research and Development program through the National Research Foundation of Korea funded by the Ministry of Science, ICT and Future Planning.

\section{REFERENCES}

1. H.-J. Im, H.-J. Cho, B.C. Song, Y.J. Park, Y.-S. Chung and W.-H. Kim, Nucl. Instr. Meth. A, 566, 442 (2006).

2. H.-J. Im, B.C. Song, Y.J. Park, Y.G. Cheun, K. Song and W.-H. Kim, J. Nucl. Sci. Technol. Suppl., 5, 364 (2008).

3. B.M. Dobratz and P.C. Crawford, LLNL Explosives Handbook Properties of Chemical Explosives and Explosive Simulants (Lawrence Livermore National Laboratory) (1985).

4. J. Yinon, Forensic and Environmental Detection of Explosives, John Wiley \& Sons, New York (1999).

5. H.-J. Im and K. Song, Appl. Spectrosc. Rev., 44, 317 (2009).

6. H.-J. Im, Y.-H. Lee, Y.J. Park, B.C. Song, J.H. Cho and W.-H. Kim, Nucl. Instr. Meth. A, 574, 272 (2007).

7. H.-J. Im, B.C. Song, Y.J. Park and K. Song, Appl. Radiat. Isot., 67, 1458 (2009).

8. E.R. Malinowski, Factor Analysis in Chemistry, Wiley, New York, edn 2 (1991).

9. Y.-H. Lee, Y.-J. Park, H.-J. Im, B.-C. Song, and W.-H. Kim, Program V2.0, Oct. 19, 2006, Reg. No. 2006-01-122-005141.

10. H.-J. Im, Y.-H. Lee, B.C. Song, Y.J. Park and W.-H. Kim, Application of Principal Component Analysis in Prompt Gamma Spectra for Material Sorting, KAERI/TR/2006. 